\title{
Surface morphology of titanium nitride thin films synthesized by $D C$ reactive magnetron sputtering
}

\author{
ŞTefan Ţălu ${ }^{1 *}$, Sebastian Stach ${ }^{2}$, Shahoo Valedbagi $^{3}$, S. Mohammad Elahi ${ }^{3}$, \\ REZA BAVADI ${ }^{3}$ \\ ${ }^{1}$ Technical University of Cluj-Napoca, Faculty of Mechanical Engineering, Department of AET, Discipline of Descriptive \\ Geometry and Engineering Graphics, 103-105 B-dul Muncii St., Cluj-Napoca 400641, Cluj, Romania \\ ${ }^{2}$ University of Silesia, Faculty of Computer Science and Materials Science, Institute of Informatics, Department of \\ Biomedical Computer Systems, Będzińska 39, 41-205 Sosnowiec, Poland \\ ${ }^{3}$ Islamic Azad University, Plasma Physics Research Center, Science and Research Branch, P.O. Box 14665-678, Tehran, Iran \\ In this paper the influence of temperature on the 3-D surface morphology of titanium nitride (TiN) thin films synthesized \\ by DC reactive magnetron sputtering has been analyzed. The 3-D morphology variation of TiN thin films grown on p-type $\mathrm{Si}$ \\ (100) wafers was investigated at four different deposition temperatures $(473 \mathrm{~K}, 573 \mathrm{~K}, 673 \mathrm{~K}, 773 \mathrm{~K})$ in order to evaluate the \\ relation among the 3-D micro-textured surfaces. The 3-D surface morphology of TiN thin films was characterized by means of \\ atomic force microscopy (AFM) and fractal analysis applied to the AFM data. The 3-D surface morphology revealed the fractal \\ geometry of TiN thin films at nanometer scale. The global scale properties of 3-D surface geometry were quantitatively esti- \\ mated using the fractal dimensions $\mathrm{D}$, determined by the morphological envelopes method. The fractal dimension $\mathrm{D}$ increased \\ with the substrate temperature variation from 2.36 (at $473 \mathrm{~K}$ ) to 2.66 (at $673 \mathrm{~K}$ ) and then decreased to 2.33 (at $773 \mathrm{~K}$ ). The \\ fractal analysis in correlation with the averaged power spectral density (surface) yielded better quantitative results of morpho- \\ logical changes in the TiN thin films caused by substrate temperature variations, which were more precise, detailed, coherent \\ and reproducible. It can be inferred that fractal analysis can be easily applied for the investigation of morphology evolution of \\ different film/substrate interface phases obtained using different thin-film technologies.
}

Keywords: atomic force microscopy $(A F M)$; DC reactive magnetron sputtering; fractal analysis; surface roughness; titanium nitride (TiN) thin film

(C) Wroclaw University of Technology.

\section{Introduction}

Titanium nitride $(\mathrm{TiN})$ is a rock-salt structure ( $\mathrm{NaCl}$ structure) compound consisting of titanium atoms contained in a face centered cubic (fcc) based lattice with all octahedral sites filled with nitrogen atoms [1]. The properties of TiN are: lattice parameter: $0.424 \mathrm{~nm}$; color: golden; density: $5.40 \mathrm{~g} / \mathrm{cm}^{3}$; melting point: $2950{ }^{\circ} \mathrm{C}$; specific heat: $37.0 \mathrm{~J} / \mathrm{mol} \cdot \mathrm{K}$; thermal conductivity: $30 \mathrm{~W} / \mathrm{m} \cdot \mathrm{K}$; thermal expansion: $9.36 \times 10^{-6} / \mathrm{K}$; electrical resistivity (bulk): $20 \pm 10 \mu \Omega \cdot \mathrm{cm}$; modulus of elasticity: $612 \mathrm{GPa}$; Young's modulus: $590 \mathrm{GPa}[2,3]$. Due to its unique properties, like high chemical stability,

*E-mail: stefan_ta@yahoo.com high hardness, good wear and corrosion resistance, TiN coatings have been used in a wide range of industrial applications, such as hard coatings, decorative coatings, wear-resistant coatings, diffusion barrier in microelectronics industry and in biomedical applications [4-9].

The mechanical properties of $\mathrm{TiN}$ film are strongly correlated with the fine grains, the crystallographic orientation, high compressive residual stresses or the dense defect-free structure of the coatings. Also, the resistivity of TiN thin films is correlated with the thickness and packing factor for all coating angles (the angle between specimen surface and the evaporation source) $[3,10,11]$. The changes in texture of the TiN thin films are due to one or a combination of factors, such as strain 
energy, surface free energy, surface diffusivity and atom mobility; the influence of each factor depends on the processing conditions [12].

Different methods were used to investigate the microroughness parameters of TiN thin films grown by DC magnetron sputtering $[13,14]$.

The aim of this study is to investigate the effect of deposition temperature on the 3-D surface morphology of TiN thin films synthesized by DC reactive magnetron sputtering through atomic force microscopy (AFM) and fractal analysis.

\section{Materials and methods}

\subsection{Materials}

TiN thin film was deposited on a p-type silicon (100) substrate by reactive DC magnetron sputtering technique in $\mathrm{Ar}+\mathrm{N}_{2}$ atmosphere. The reactive sputter gas was a mixture of argon (99.999\%) and nitrogen $(99.999 \%)$ with the ratio $\operatorname{Ar}(97 \%)$ and $\mathrm{N}_{2}(3 \%)$ by volume. This system consisted of planar Ti metal target (99.99\% purity) with $5 \mathrm{~cm}$ diameter. The distance between the wafer and the target was $3 \mathrm{~cm}$. The growth chamber was initially evacuated up to a pressure of $1 \times 10^{-3} \mathrm{~Pa}$ by a rotary pump (ALCATEL) and diffusion pumps. Then, a gas mixture of $97 \%$ argon and $3 \%$ nitrogen was introduced into the chamber. The pressure in the sputter chamber during the growth of all samples was constant, equal to $2.66 \mathrm{~Pa}$ and current density was $10 \mathrm{~mA} / \mathrm{cm}^{2}$. The substrate was heated in the vacuum chamber and the temperature of the substrate was measured with a thermocouple. The deposition process was performed in 3 stages at different substrate temperatures $(473 \mathrm{~K}, 573 \mathrm{~K}, 673 \mathrm{~K}$, $773 \mathrm{~K}$ ), respectively, and the deposition time for all samples was $120 \mathrm{~min}$.

\subsection{Methods}

All AFM images were recorded in a contact mode, in air, using an atomic force microscope (Digital Instruments, Mod. Nanoscope E, USA). The measurements were performed using silicon nitride AFM tips (Digital Instruments). The experiments were conducted in the same room, at room temperature $(297 \pm 1 \mathrm{~K})$, ambient pressure and $(50 \pm 1 \%)$ relative humidity. Scanning was performed at a scan speed of $1 \mathrm{~Hz}$. The measurements were repeated for three times for each sample on different reference areas, to validate the reproducibility of these features. Images with $256 \times 256$ pixels definition were converted to uncompressed linear 8-bit gray scale TIF format for further analyses. Detailed surface characterization of the AFM images was obtained using Digital Surf MountainsMap ${ }^{\circledR}$ Premium software version 7 (Digital Surf, Besançon, France) [15].

\subsection{Fractal analysis of the 3-D micro- textured surface}

The morphology and sizes of 3-D micro/nano structures can be characterized using several methods, more appropriate for quantifying complex structures than traditional Euclidean geometry and surface statistical functions [4, 12, 16, 17].

Fractal geometry, and its concepts of selfsimilarity and non-integer dimensionality, is a suitable tool to estimate 3-D complex morphologies [13, 16, 18-21]. Fractal methods measure quantitatively the self-similarity (a restricted case of a more general class, self affinity) of fractal objects, having the advantage to be insensitive to the structural details $[16,18]$.

There are several formal mathematical definitions of fractal dimension that can be estimated by several techniques based on different mathematical algorithms [16, 18-22]. Furthermore, the fractal dimension characterizes the degree of irregularity and complexity of a space-filling capacity of a fractal object [22, 23].

A fractal surface is continuous, self-similar, but non-differentiable [19]. It is known that the 3-D fractal surfaces remain statistically self-similar over a restricted range of length scales [18]. A 3-D fractal surface is characterized by a single quantitative descriptor, the fractal dimension D (a non-integer value within a range of $2 \leqslant \mathrm{D} \leqslant 3$ ) which is a measure of the structure complexity that can provide insight into how the structure is formed [16, 18].

Higher values of D correspond to a higher level of structural complexity and irregularity of the 
surface $[16,18]$. A recent study highlighted a correlation between the different surface roughness parameters of $\mathrm{TiN}$ thin films and the surface fractal dimension D [13].

In this study, the fractal analysis was applied to the original AFM files using an algorithm that has been previously described in detail [24-26]. On the other hand, the estimation of fractal dimension (determined by the morphological envelopes method) of the AFM images was carried out using MountainsMap ${ }^{\circledR}$ Premium software version 7 [15].

\subsection{Statistical analysis}

Statistical analyses were carried out using the STATISTICA 12 software package (StatSoft Inc., USA) [27]. Comparisons among different areas within the same sample were performed using independent samples T-test. When statistical significance was found, the difference between two groups was further compared using the MannWhitney $\mathrm{U}$ test. The average $\mathrm{D}$ results were expressed as a mean value and standard deviation.

\section{Results}

A set of representative 2-D topographic (top view) AFM images of the grown layers, for a square area of $1 \mu \mathrm{m} \times 1 \mu \mathrm{m}$, at temperatures: (a) $473 \mathrm{~K}$, (b) $573 \mathrm{~K}$, (c) $673 \mathrm{~K}$ and (d) $773 \mathrm{~K}$, is shown in Fig. 1. The AFM image is color coded (in [nm]) to represent the vertical (height) scale of different points and the color code is indicated on the bar on the right hand side.

The peak count distribution histograms indicate a distribution of peaks according to the height of a planar section. The distribution reports the number of grains (areas corresponding to peaks) that are situated above the plane. The horizontal axis is graduated in height from the lowest to the highest point and the vertical axis can display the number of peaks or the density, i.e. the number of peaks per unit area [15]. The peak count histograms associated with Fig. 1 are shown in Fig. 2.

The periodicity and orientation of certain patterns that exist on the surface in addition to the roughness can be determined using a spectral analysis, by showing the wavelengths found in the spectrum [15]. This spectrum is computed using the Fourier Transform.

The averaged power spectral density (surface) of TiN grown layers nanostructures obtained at temperatures: (a) $473 \mathrm{~K}$, (b) $573 \mathrm{~K}$, (c) $673 \mathrm{~K}$ and (d) $773 \mathrm{~K}$, was calculated for scanning square areas of $1 \times 1 \mu \mathrm{m}^{2}$ (Fig. 3). In graphical representations, the horizontal axis is graduated in wavelengths, and the vertical axis displays the amplitude to a power of 2 .

A summary of the fractal dimensions with coefficients of correlation $\left(\mathrm{R}^{2}\right)$ determined by the morphological envelopes method is shown in Table 1. The coefficients of correlation $\left(\mathrm{R}^{2}\right)$ of all linear fits are equal to or greater than 0.995 , representing a good linear correlation.

\section{Discussion}

The surface topography of the TiN thin films prepared by reactive DC magnetron sputtering was investigated by means of AFM. These thin films have a 3-D surface topography with heterogeneous nanostructures (different shapes and sizes) that can be estimated globally by means of the fractal geometry (Fig. 1).

Averaged power spectrum density shows wavelengths dominant on the surface and their amplitudes (Fig. 3). In the power spectral density study of TiN nanostructures in the grown layers (Fig. 3), the dominant wavelength was found at $0.145 \mu \mathrm{m}$ for all cases, with the following amplitudes: (a) $0.358 \mathrm{~nm}$ (at $473 \mathrm{~K}$ ), (b) $1.39 \mathrm{~nm}$ (at $573 \mathrm{~K}$ ), (c) $2.54 \mathrm{~nm}($ at $673 \mathrm{~K}$ ) and (d) $2.06 \mathrm{~nm}$ (at $773 \mathrm{~K}$ ). It can be seen that for the dominant wavelength $(0.145 \mu \mathrm{m})$, the amplitude increases from $0.358 \mathrm{~nm}$ (at $473 \mathrm{~K}$ ) to $2.54 \mathrm{~nm}$ (at $673 \mathrm{~K}$ ), then it decreases to $2.06 \mathrm{~nm}$ (at $773 \mathrm{~K}$ ).

Furthermore, the morphology pattern of nanoasperities is quantified by specific fractal dimension (determined by the morphological envelopes method) (Table 1). The fractal dimensions increases from $\mathrm{D}=2.36 \pm 0.0127$ (at $473 \mathrm{~K}$ ) to $\mathrm{D}=2.66 \pm 0.0129$ (at $673 \mathrm{~K})$, then it decreases to $\mathrm{D}=2.33 \pm 0.0124$ (at $773 \mathrm{~K}$ ). 


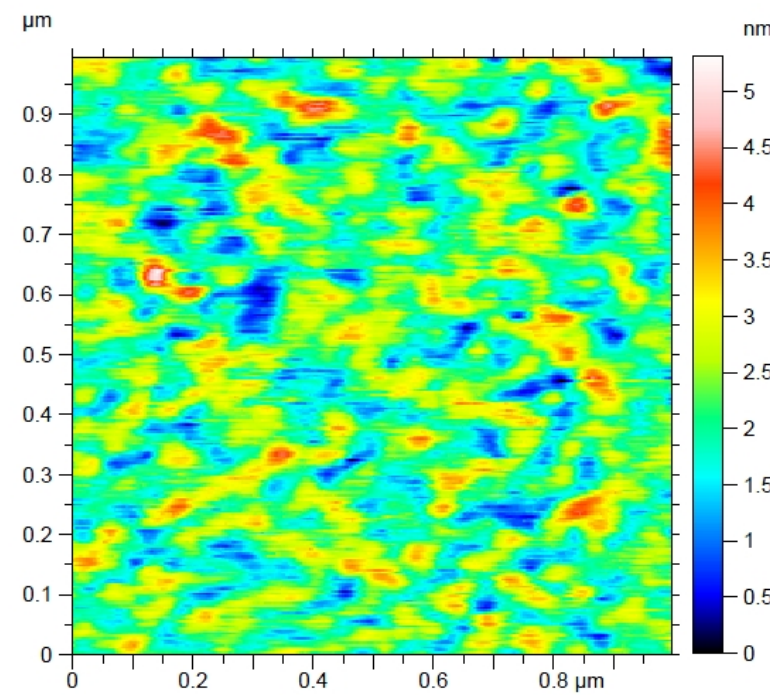

(a)

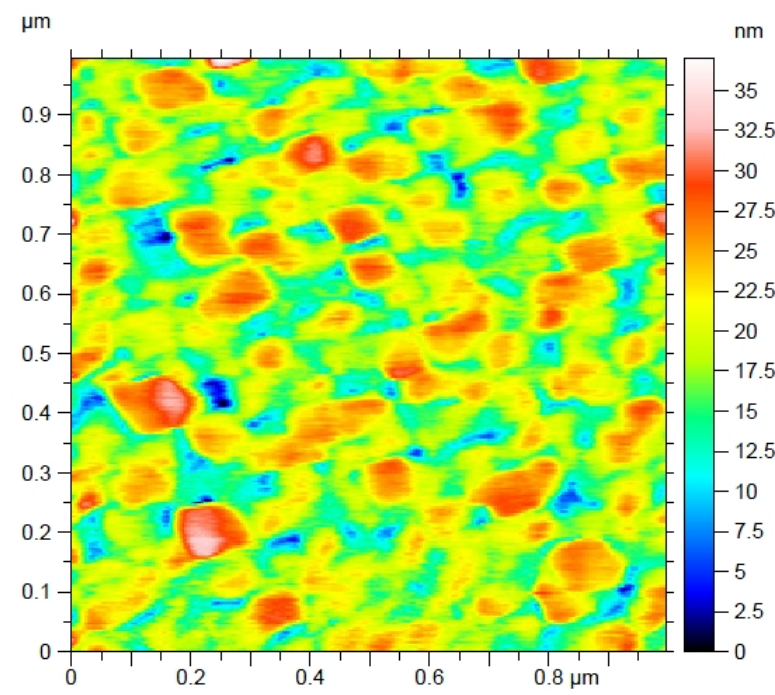

(c)

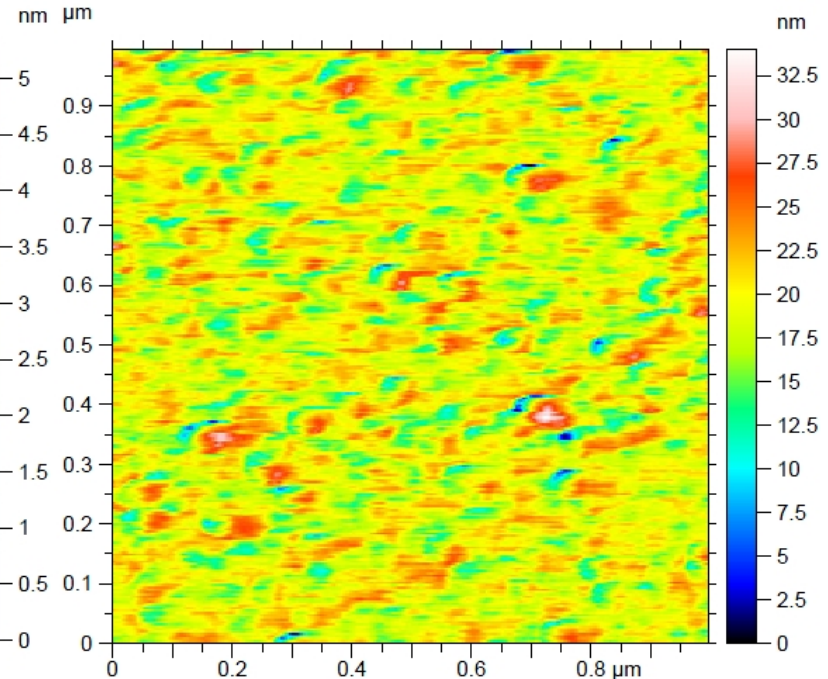

(b)

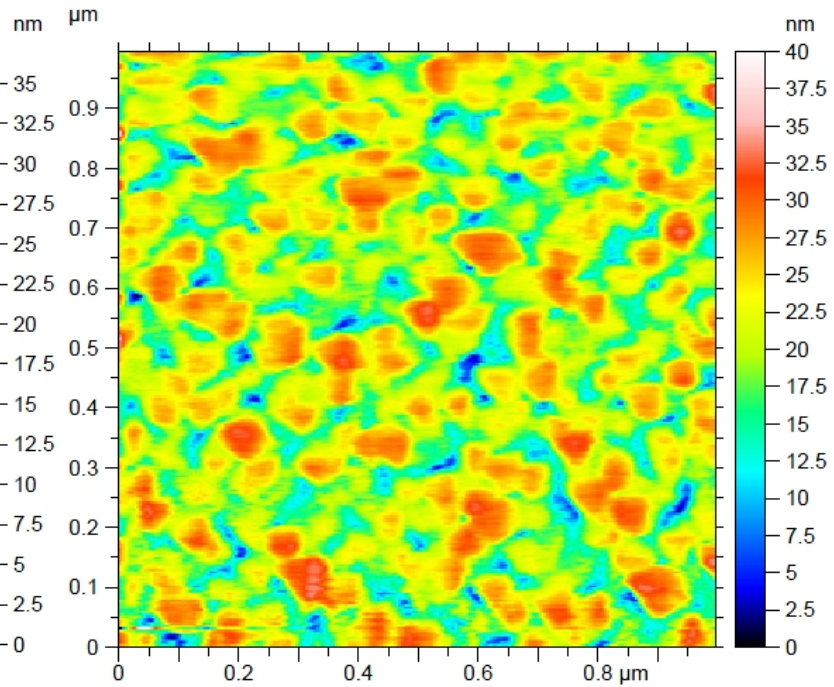

(d)

Fig. 1. A set of representative 2-D topographic (top view) AFM images of the layers, grown at temperatures: (a) $473 \mathrm{~K}$, (b) $573 \mathrm{~K}$, (c) $673 \mathrm{~K}$ and (d) $773 \mathrm{~K}$. The z-position information is color-coded according to the color scale bar displayed on the right hand side of the AFM image.

Table 1. The fractal dimensions (D) with coefficients of correlation $\left(\mathrm{R}^{2}\right)$ determined by the morphological envelopes method, for nanostructures of TiN layers grown at temperatures: (a) $473 \mathrm{~K}$, (b) $573 \mathrm{~K}$, (c) $673 \mathrm{~K}$ and (d) $773 \mathrm{~K}$ for scanning square areas of $1 \times 1 \mu^{2}$.

\begin{tabular}{ccccc}
\hline \multirow{2}{*}{ Parameters } & \multicolumn{4}{c}{ Substrate temperature } \\
\cline { 2 - 5 } & $473 \mathrm{~K}$ & $573 \mathrm{~K}$ & $673 \mathrm{~K}$ & $773 \mathrm{~K}$ \\
\hline \hline $\mathrm{D}$ & $2.36 \pm 0.0127$ & $2.60 \pm 0.0125$ & $2.66 \pm 0.0129$ & $2.33 \pm 0.0124$ \\
$\mathrm{R}^{2}$ & 0.997 & 0.995 & 0.996 & 0.997 \\
\hline
\end{tabular}




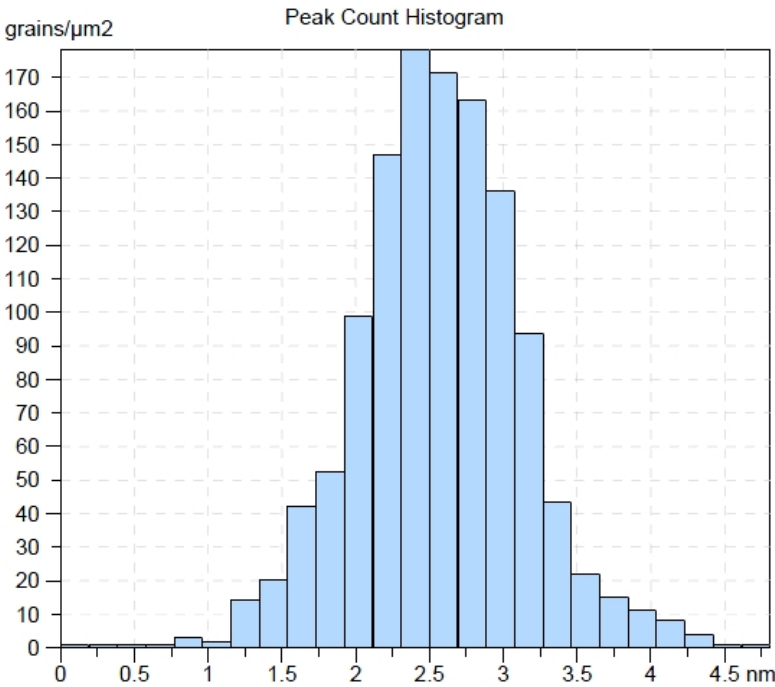

(a)

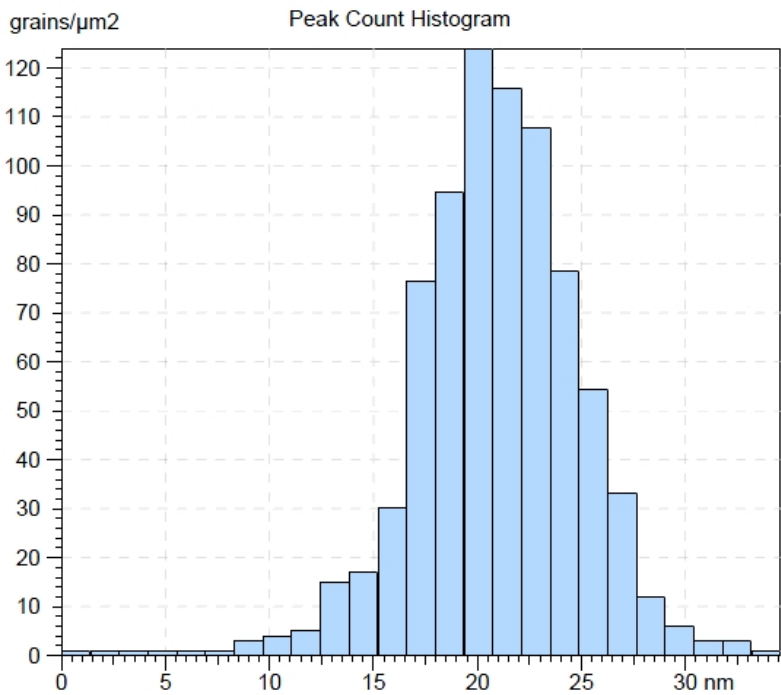

(c)

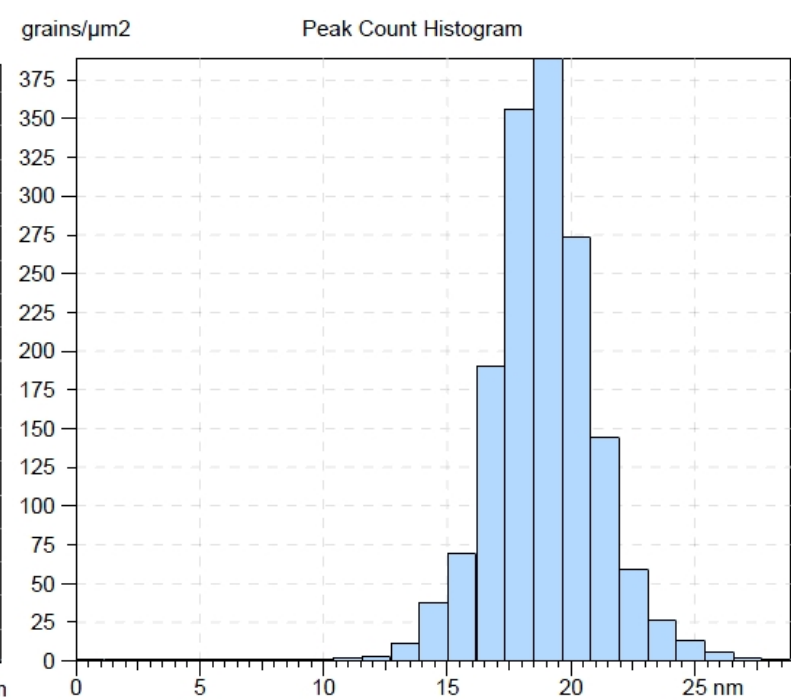

(b)

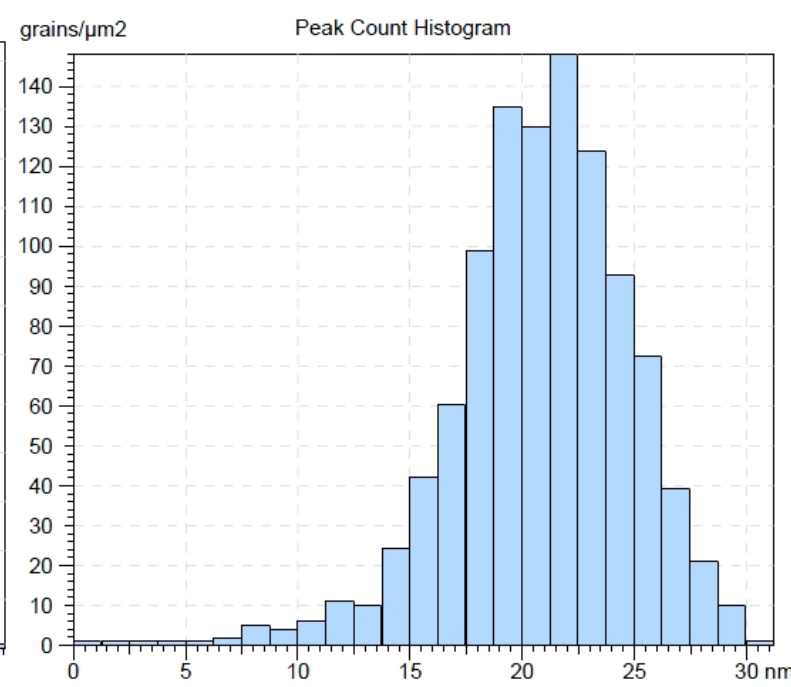

(d)

Fig. 2. The peak count histograms of TiN layers, grown at temperatures: (a) $473 \mathrm{~K}$, (b) $573 \mathrm{~K}$, (c) $673 \mathrm{~K}$ and (d) $773 \mathrm{~K}$, for a square area of $1 \mu \mathrm{m} \times 1 \mu \mathrm{m}$.

\section{Conclusions}

In the study, we analyzed the temperature influence on the 3-D surface morphology of titanium nitride (TiN) thin films synthesized by DC reactive magnetron sputtering.

Our results suggest that characteristic topographic parameters, like fractals, in correlation with the averaged power spectral density (surface) are useful tools to characterize the surface morphology of (TiN) thin films, prepared by reactive DC magnetron sputtering. Furthermore, the atomic-scale understanding of microstructures evolution allows controlling and tailoring the properties and performance of the thin films. This study confirms the results obtained by Bavadi and Valedbagi [3], where the grain size was evaluated by Scherrer's formula and XRD patterns and these ones were in agreement with the calculated grain size of AFM images. In addition, the fractals 


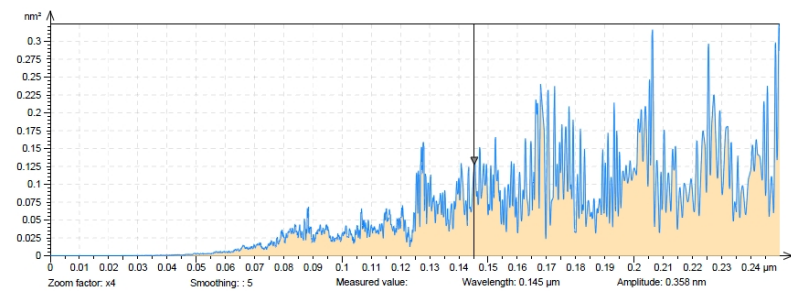

(a)

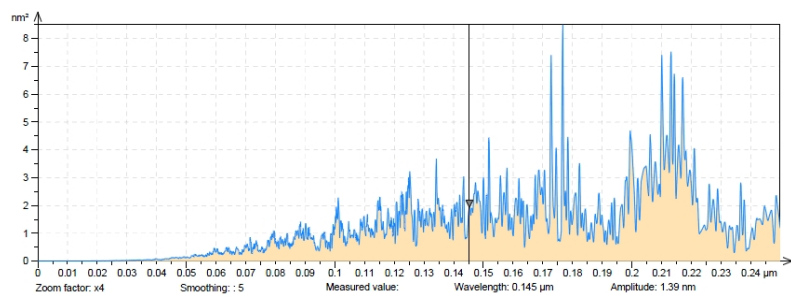

(b)

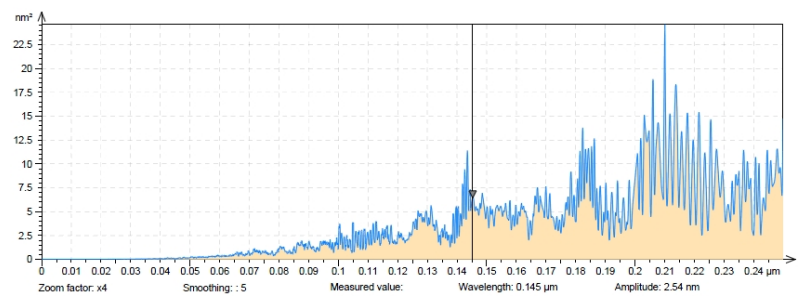

(c)

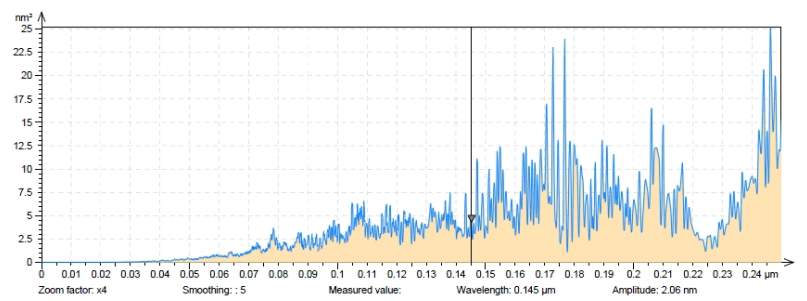

(d)

Fig. 3. The averaged power spectral density (surface) of TiN layers grown at temperatures: (a) $473 \mathrm{~K}$, (b) $573 \mathrm{~K}$, (c) $673 \mathrm{~K}$ and (d) $773 \mathrm{~K}$, for a square area of $1 \mu \mathrm{m} \times 1 \mu \mathrm{m}$.

characteristics can also be used to develop new mathematical and numerical models of 3-D growth processes of $\mathrm{TiN}$ layers.

\section{References}

[1] Xu X., Ye H., Zou T., J. Zhejiang Univ.-Sci. A, 7 (3) (2006), 472.

[2] LEClaIR P. R., PhD. Thesis: Titanium Nitride thin films by the electron shower process, Massachusetts Institute of Technology, USA, 1998.
[3] Bavadi R., Valedbagi S., Mater. Phys. Mech., 15 (2012), 167.

[4] Pankiew A., Bunjongpru W., Somwang N., Porntheeraphat S., Sopitpan S., Nukaew J., Hruanun C., Poya A., J. Micros. Soc. Thail., 24 (2) (2010), 103.

[5] Tao M., Udeshi D., Agarwal S., Maldonado E., Solid State Electron., 48 (2004), 335.

[6] Smith G.B., Ben-David A., Swift P.D., Renew. Energ., 22 (1 - 3) (2001), 79.

[7] Vaz F., Cerqueira P., Rebouta L., Nascimento S.M. C., Alves E., Goudeau P.H., Riviere J.P., Pischow K., DE RiJK J., Thin Solid Films, 447 - 448 (2004), 449.

[8] Borah S.M., Pal A.R., Bailung H., Chutia J., Appl. Surf. Sci., 254 (18) (2008), 5760.

[9] Serro A.P., Completo C., Colaço R., Dos Santos F., DA Silva C. Lobato, Cabral J.M. S., Araújo H., Pires E., Saramago B., Surf. Coat. Tech., 203 (24) (2009), 3701.

[10] Chou W.J., Yu G.P., Huang J.H., Surf. Coat. Tech., 140 (3) (2001), 206.

[11] Tamura M., Kubo H., Surf. Coat. Tech., 49 (1 - 3) (1991), 194.

[12] Chawla V., Jayaganthan R., Chandra R., Mater. Charact., 59 (2008), 1015.

[13] Gelali A., Ahmadpourian A., Bavadi R., Hantehzadeh M.R., Ahmadpourian A., J. Fusion Energ., 31 (2012), 586.

[14] Hantehzadeh M.R., BaVAdi R., SARI A.H., GHoRANNEVISS M., J. Fusion Energ., 30 (4) (2011), 333.

[15] MountainsMap ${ }^{\circledR} 7$ Software (Digital Surf, Besançon, France). Available at: http://www.digitalsurf.fr (last accessed on September 10, 2014).

[16] Zolotarevski S.Y., Novikov D.A., Gusev A.S., LyASKOVSKII V.L., Meas. Tech.+, 56 (3) (2013), 247.

[17] Almtoft K.P., PhD Thesis: Structural characterization of nanocrystalline thin films grown by magnetron sputtering, University of Aarhus, Denmark, 2006.

[18] YadaV R.P., Dwivedi S., Mittal A.K., Kumar M., PANDEY A.C., Appl. Surf. Sci., 261 (2012), 547.

[19] Ţălu Ş., Ghazai A. J., Stach S., Hassan A., HasSAN Z., ŢĂLU M., J. Mater. Sci.-Mater. El., 25 (1) (2014), 466.

[20] Dallaeva D., Ţălu Ş., Stach S., ŠKarVada P., ToMÁneK P., GrMela L., Appl. Surf. Sci., 312 (2014), 81.

[21] Țălu Ş., Stach S., Zaharieva J., Milanova M., Todorovsky D., Giovanzana S., Int. J. Polym. Anal. Ch., 19 (5) (2014), 404.

[22] ŢăLU Ş., Anim. Biol. Anim. Husb., 4 (2012), 1.

[23] Ţălu Ş., Stach S., Ikram M., Pathak D., WagNER T., NUnZI J.-M., Int. J. Nanosci., (2014). DOI: 10.1142/S0219581X14500203.

[24] Stach S., Roskosz S., Cybo J., Cwajna J., Mater. Charact., 60 (2009), 1151.

[25] Chhabra A., Jensen R.V., Phys. Rev. Lett., 62 (1989), 1327. 
[26] Lou S., Jiang X., ScotT P.J., Measurement, 46 (2) (2013), 1002.

[27] STATISTICA software, version 12 (StatSoft Inc., USA). Available at: http://www.statsoft.com (last ac-

Received 2014-07-25 cessed on September 10, 2014). 